\title{
Spermiogenesis and spermatozoon of the liver fluke Mediogonimus jourdanei (Microphalloidea: Prosthogonimidae), a parasite of Myodes glareolus (Rodentia: Cricetidae)
}

\author{
Abdoulaye J.S. Bakhoum ${ }^{1,2}$, Carlos Feliu' ${ }^{1,2}$, Cheikh Tidiane Bâ ${ }^{3}$ and Jordi Miquel ${ }^{1,2}$ \\ ${ }^{1}$ Laboratori de Parasitologia, Departament de Microbiologia i Parasitologia Sanitàries, Facultat de Farmàcia, Universitat de \\ Barcelona, Av. Joan XXIII, s/n, E-08028 Barcelona, Spain; \\ ${ }^{2}$ Institut de Recerca de la Biodiversitat, Facultat de Biologia, Universitat de Barcelona, Av. Diagonal, 645, E-08028 Barcelona, \\ Spain; \\ ${ }^{3}$ Laboratoire de Parasitologie-Helminthologie, Département de Biologie animale, Faculté des Sciences et Techniques, Université \\ Cheikh Anta Diop de Dakar, B.P. 5005, Dakar, Senegal
}

\begin{abstract}
Spermatological characters of the liver fluke Mediogonimus jourdanei Mas-Coma et Rocamora, 1978 were studied by means of transmission and scanning electron microscopy. Spermiogenesis begins with the formation of the differentiation zone containing two centrioles associated with striated rootlets and an intercentriolar body. These two centrioles originate two free flagella that undergo a $90^{\circ}$ rotation before fusing with the median cytoplasmic process. Both nuclear and mitochondrial migrations toward the median cytoplasmic process occur before the proximodistal fusion of flagella. Finally, the constriction of the ring of arched membranes gives rise to the young spermatozoon. The mature sperm of $M$. jourdanei measures about $260 \mu \mathrm{m}$ and presents two axonemes of different lengths with the typical pattern of the Trepaxonemata, two bundles of parallel cortical microtubules, one mitochondrion, a nucleus and granules of glycogen. An analysis of all the microphalloidean species studied to date emphasised some differences in certain characters found in Maritrema linguilla Jägerskiöld, 1908 and Ganeo tigrinum Mehra et Negi, 1928 in comparison to those in the remaining microphalloideans. The presence and variability of such ultrastructural characters according to family, superfamily or order have led several authors to propose their use in the analysis of trematode relationships and phylogeny. Therefore, apart from producing new data on the family Prosthogonimidae, the present study also compares the spermatological organization of $M$. jourdanei with other available ultrastructural studies focusing on the Microphalloidea.
\end{abstract}

Keywords: Mediogonimus jourdanei, Prosthogonimidae, Microphalloidea, Digenea, ultrastructure, SEM, TEM, spermiogenesis, spermatozoon

The genus Mediogonimus Woodhead et Malewitz, 1936 includes liver parasites of arvicoline and murine rodents from North America and Europe (see Jones 2008). To date, this genus includes only two species, namely $M e$ diogonimus ovilacus Woodhead et Malewitz, 1936 and Mediogonimus jourdanei Mas-Coma et Rocamora, 1978. The genus Mediogonimus was initially placed in the subfamily Prosthogoniminae Lühe, 1909 in the family Prosthogonimidae Lühe, 1909. Later, other authors included this subfamily in the family Plagiorchiidae Lühe, 1901 or Lepodermatidae Odhner, 1910 (now synonymized with Plagiorchiidae). The classification and taxonomic status of Prosthogonimidae have varied considerably according to authors. The Prosthogonimidae have been considered a family closely related to the Cephalogonimidae Looss, 1899 , both families included in the superfamily Plagiorchioidea Lühe, 1901, due to morphoanatomical aspects (see Jones 2008). Brooks et al. (1989), who accept the latter family status, propose placing it in the superfamily Microphalloidea Ward, 1901, although it is unclear how they reached this conclusion based on their morphological phylogenetic analysis (see Cribb et al. 2001). Recently, the relationship between cephalogonimids and prosthogonimids was not corroborated by molecular analysis (Olson et al. 2003). According to the latter authors, they represent different clades and prosthogonimids are the sister group of the microphalloidean family Pleurogenidae Travassos, 1921. These results are in agreement with Jones (2008) who considers that the family Prosthogonimidae should belong to the superfamily Microphalloidea.

The controversies concerning this family are common to most digenean taxa, being recurrent problems to the establishment of relationships within the Platyhelminthes. In order to help clarifying such relationships in the Platy- 
helminthes, several authors suggest the use of reproduction-related ultrastructural characters (spermiogenesis and/or spermatozoon) (Brooks et al. 1985, Bâ and Marchand 1995, Justine 1998, 2001, 2003, Levron et al. 2010). Concerning digeneans, the use of ultrastructural characters for phylogenetic purposes is not yet applied basically due to: (i) the insufficient amount of ultrastructural studies and (ii) the great diversity of this class, containing about 18,000 species (see Cribb et al. 2001). However, the recent increase of ultrastructural studies allowed proposing several characters as potentially useful to phylogenetic inferences (Levron et al. 2004b, Miquel et al. 2006, Bakhoum et al. 2009, Ternengo et al. 2009). The aim of the present study is to produce the first data on the family Prosthogonimidae, contributing to the ultrastructural database concerning the Digenea. We also compare our results with the available data on digenean spermatology, in particular with those species belonging to the superfamily Microphalloidea.

\section{MATERIALS AND METHODS}

A naturally infected bank vole, Myodes glareolus (Schreber, 1780) was captured in the Nature Reserve of Py (Pyrenean Mountains, France) during June 2009. Live mature specimens of Mediogonimus jourdanei were collected from the liver and placed in a $0.9 \% \mathrm{NaCl}$ solution and routinely processed for TEM and SEM examination.

\section{Transmission electron microscopy (TEM) examination}

After dissection, specimens were fixed in cold $\left(4^{\circ} \mathrm{C}\right) 2.5 \%$ glutaraldehyde in a $0.1 \mathrm{M}$ sodium cacodylate buffer at $\mathrm{pH} 7.4$ for $2 \mathrm{~h}$, rinsed in a $0.1 \mathrm{M}$ sodium cacodylate buffer at $\mathrm{pH} 7.4$, postfixed in cold $\left(4^{\circ} \mathrm{C}\right) 1 \%$ osmium tetroxide in the same buffer for $1 \mathrm{~h}$, rinsed in a $0.1 \mathrm{M}$ sodium cacodylate buffer at $\mathrm{pH} 7.4$, dehydrated in an ethanol series and propylene oxide, and finally embedded in Spurr's resin. Ultrathin sections were obtained using a Reichert-Jung Ultracut Electronic ultramicrotome, placed on copper grids and double-stained with uranyl acetate and lead citrate according to Reynolds (1963).

Gold grids were made to reveal the presence of glycogen according the Thiéry (1967) methodology. Ultrathin sections placed on gold grids were treated in periodic acid, thiocarbohydrazide, and silver proteinate (PA-TCH-SP) as follows: 30 min in $10 \% \mathrm{PA}$, rinsed in Milli-Q water, $24 \mathrm{~h}$ in $\mathrm{TCH}$, rinsed in acetic solutions and Milli-Q water, 30 min in 1\% SP in the dark, and rinsed in Milli-Q water.

All ultrathin sections were examined using a JEOL 1010 transmission electron microscope operated at $80 \mathrm{kV}$.

\section{Scanning electron microscopy (SEM) examination}

Sections of flukes containing seminal vesicle were placed in Tyrode solution to allow for the liberation of the spermatozoa (Bedford 1975). Thus, the solution containing living spermatozoa was fixed in cold $\left(4^{\circ} \mathrm{C}\right) 8 \%$ glutaraldehyde in $0.1 \mathrm{M}$ phosphate buffer at $\mathrm{pH} 7.4$ (1 volume of sample with 3 volumes of fixative). Then, the solution was placed in a centrifuge at 500 to $1000 \mathrm{rpm}$. After agitation the solution was postfixed in cold $\left(4^{\circ} \mathrm{C}\right) 2 \%$ glutaraldehyde, rinsed in $0.1 \mathrm{M}$ phosphate buffer at $\mathrm{pH}$ 7.4 and in MilliQ water. Later, $100 \mu 1$ of this solution was deposited on cover glasses with poly-L-lysine before dehydration in an alcohol series. The samples were critical-point-dried with a Polaron CPD 7501 system (VG Microtech, UK), using hexamethyldisilazane before coating with gold (15-20 nm thick) using a SC510 sputter coater (Fisons Instruments). Finally, samples were examined using a Zeiss DSM 940 scanning electron microscope at $15 \mathrm{kV}$ to a distance of $4 \mathrm{~mm}$.

\section{RESULTS}

\section{Spermiogenesis}

The beginning of the spermiogenesis of Mediogonimus jourdanei is marked by the formation of the differentiation zone. This zone is bordered by cortical microtubules and contains the nucleus, an intercentriolar body located between two centrioles, which will originate two free flagella (Figs. 1a, c, 3a). The intercentriolar body consists of seven electron-dense layers, with three thicker dark external plates on each side of a thinner central plate (Fig. 1b). A cross-section of the differentiation zone in an early stage of spermiogenesis exhibits the median cytoplasmic process, nucleus, centrioles, intercentriolar body, and cortical microtubules (Fig. 1c). After their orthogonal growth, both flagella begin their rotation to become parallel to the median cytoplasmic process (Figs. 1a, d, e, 3a, b). Crosssections at this stage show the median cytoplasmic process containing a nucleus, a mitochondrion and two fields of cortical microtubules, along with two external free flagella on each side of the median cytoplasmic process (Fig. 1f). In distal areas of the differentiation zone before the fusion, several cross-sections show the median cytoplasmic processes and the free flagella (Fig. 2a). The asynchronous fusion of flagella with the median cytoplasmic process is demonstrated in cross-sections exhibiting the nucleus, one axoneme, and a mitochondrion while the other flagellum is still free (Fig. 2b).

After the fusion of both flagella, the ring of arched membranes initiates its constriction. In an early stage of this progressive constriction process, the striated rootlets are still present in the spermatid body. At this stage, both longitudinal and cross-sections show that mitochondria are still migrating (Fig. 2c, d). Finally, in a terminal stage of the constriction process, striated rootlets disappear and the young spermatozoon detaches from the residual cytoplasm (Figs. 2e, 3d).

\section{Spermatozoon}

The ultrastructural aspects of the mature spermatozoon of $M$. jourdanei are illustrated in Figs. 4-6. The spermatozoon is filiform and measures about $260 \mu \mathrm{m}$ (Fig. 4a). It is characterized by the presence of two axonemes of different lengths exhibiting the $9+$ " 1 " trepaxonematan pattern, a nucleus, one mitochondrion, two sets of parallel submembranous cortical microtubules, an external ornamentation, spine-like bodies and granules of glycogen (Fig. 5a-r). The interpretation of several cross and longitudinal sections allows us to establish three distinctive regions from the anterior to the posterior extremity of the spermatozoon of $M$. jourdanei. 

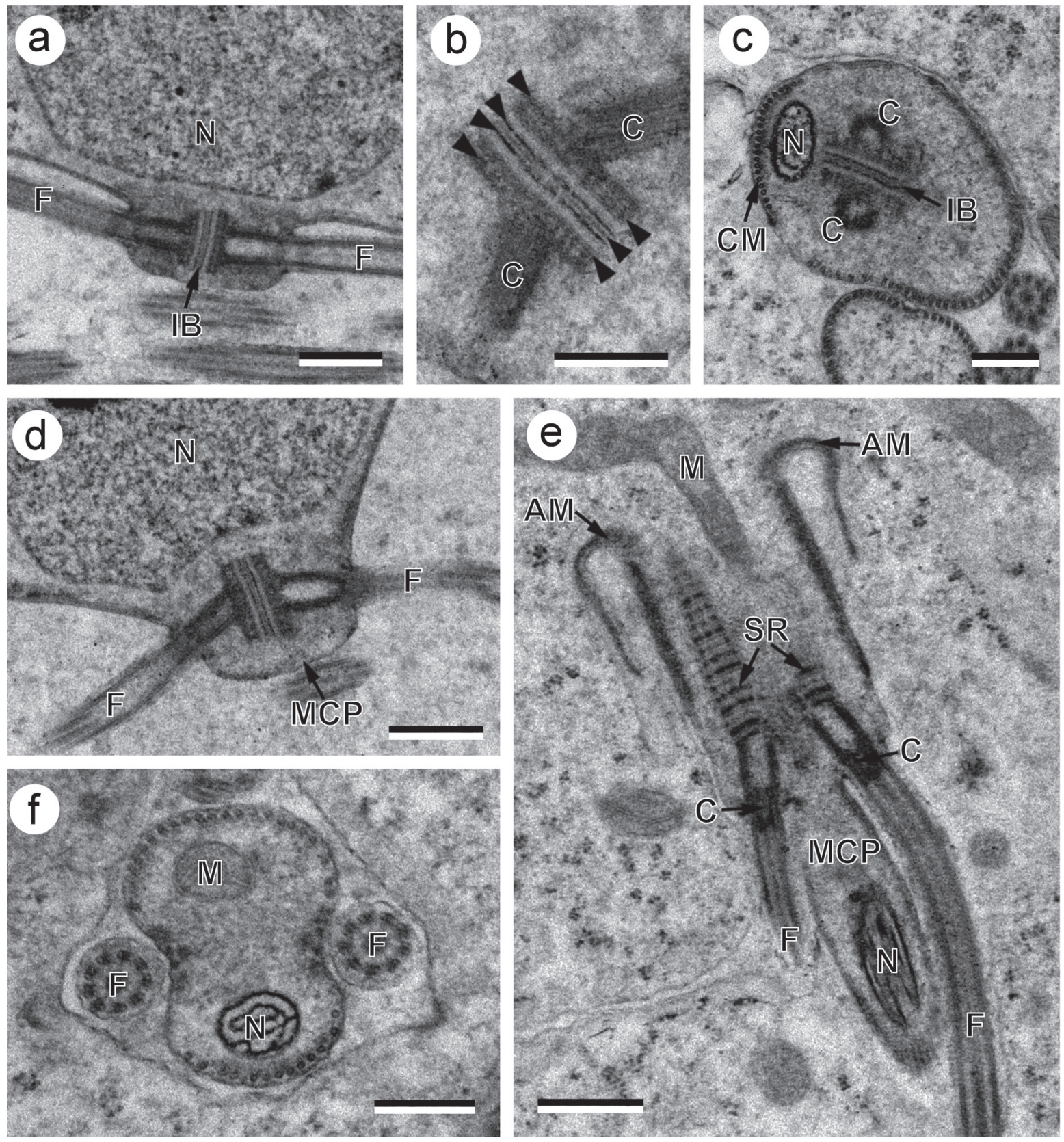

Fig 1. Transmission electron micrographs of spermiogenesis of Mediogonimus jourdanei. a - Initial stage of the zone of differentiation showing the development of the two flagella; $\mathbf{b}$-Detail of the intercentriolar body; $\mathbf{c}$-Cross-section of the differentiation zone at the level of centrioles; $\mathbf{d}$ - Intermediate stage during flagellar rotation; $\mathbf{e}$ - Longitudinal section showing the two flagella parallel to the median cytoplasmic process; $\mathbf{f}$ - Cross-section before flagellar fusion showing nuclear and mitochondrial migrations. Abbreviations: AM - arched membranes; C - centriole; CM - cortical microtubules; F - flagellum; IB - intercentriolar body; $\mathrm{M}$ - mitochondrion; $\mathrm{MCP}$ - median cytoplasmic process; $\mathrm{N}$ - nucleus; $\mathrm{SR}$ - striated rootlets. Scale bars: $\mathrm{a}-\mathrm{f}=0.5 \mu \mathrm{m}$.

\section{Region I}

It corresponds to the anterior spermatozoon extremity presenting a sharp morphology (Figs. 4b, 5a, b, 6I). Both longitudinal and cross-sections in this region show centrioles surrounded by a continuous layer of parallel cortical microtubules (Figs. 5c, d, 6I). Cross-sections in more posterior areas of the anterior spermatozoon extremity exhibit two axonemes also surrounded by a continuous layer of cortical microtubules (about 34 to 39). Note that in this area the attachment zones are not observed (Fig. $5 \mathrm{e})$. The central part of region I is an ornamented zone, characterized by the presence of external ornamentation of the plasma membrane associated with cortical microtubules and spine-like bodies (Figs. 5f, g, 6I). Moreover, the external ornamentation appears only in those areas where the cortical microtubules are present and surrounds one 

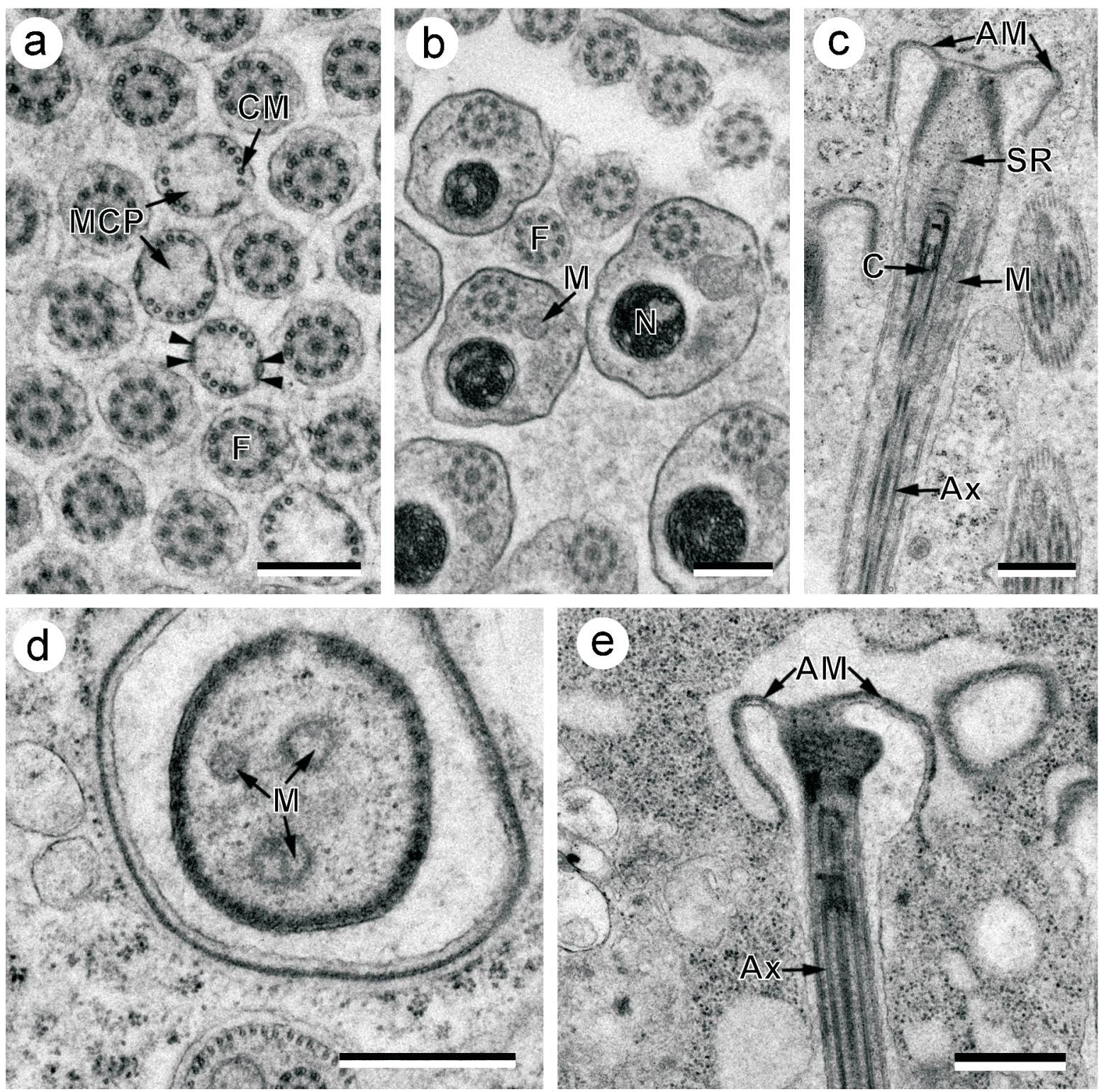

Fig 2. Transmission electron micrographs of spermiogenesis of Mediogonimus jourdanei. a - Cross-sections showing median cytoplasmic processes before their fusion with flagella; arrowheads indicate attachment zones; $\mathbf{b}$-Several cross-sections showing the asynchronous fusion of flagella; $\mathbf{c}$ - Longitudinal section after flagellar rotation; note the mitochondrial migration and the presence of striated rootlets; $\mathbf{d}$-Cross-section at the level of arched membranes showing several mitochondria; $\mathbf{e}$-Advanced stage during the constriction of the ring of arched membranes; note the absence of striated rootlets. Abbreviations: AM - arched membranes; $\mathrm{Ax}$ - axoneme; $\mathrm{C}$ - centriole; $\mathrm{CM}$ - cortical microtubules; $\mathrm{F}$ - flagellum; $\mathrm{M}$ - mitochondrion; $\mathrm{MCP}$ - median cytoplasmic process; $\mathrm{N}$ - nucleus; $\mathrm{SR}-$ striated rootlets. Scale bars: $\mathrm{a}, \mathrm{b}, \mathrm{d}=0.3 \mu \mathrm{m} ; \mathrm{c}, \mathrm{e}=0.5 \mu \mathrm{m}$.

of the axonemes (Figs. 5f, 6I). It is also noticeable that only two attachment zones are present in this area (Figs. $5 \mathrm{f}, 6 \mathrm{I})$. The end of region I is marked by the presence of cortical microtubules organized in two fields and by the appearance of granules of glycogen (Figs. 5h, i, 6I). Glycogen has been evidenced by the cytochemical test of Thiéry (Fig. 5r). This zone that exhibits another four attachment zones marks the transition between regions I and II (Figs. 5h, i).

\section{Region II}

In this region the mitochondrion is accompanied by the nucleus, both axonemes and a reduced number of cortical microtubules present in a nuclear or dorsal face (about 4-5) and in a mitochondrial or ventral face (about 7) (Figs. $4 c, 5 j-1,6 I I)$. Granules of glycogen are also observed in this area. When the diameter of the nucleus increases, the cortical microtubules form two lateral bundles (Fig. 51, $\mathrm{m})$. The posterior part of region II is characterized by the 
disappearance of one axoneme. At this level, it is possible to observe the axoneme, nucleus, mitochondrion, granules of glycogen and a reduced number of cortical microtubules (about 2-4) (Figs. 5m, 6II).

\section{Region III}

It corresponds to the posterior spermatozoon extremity, being characterised by the disappearance of the mitochondrion and cortical microtubules, and showing only a single axoneme, the nucleus and granules of glycogen (Figs. $5 \mathrm{n}, 6 \mathrm{III})$. Several cross-sections toward the posterior extremity exhibit the progressive reduction of the nucleus diameter and its disappearance. The posterior extremity of the nucleus was also observed by means of SEM (Fig. 4d). Finally, the single axoneme begins its disorganization characterised by the presence of doublets and singlets that reach the posterior spermatozoon extremity (Figs. 5o-q, 6 III). The posterior tip of the spermatozoon exhibits only singlets and some granules of glycogen (Figs. 5q, 6III).

\section{DISCUSSION}

\section{Spermiogenesis}

Despite the great similarities observed between the spermiogenesis processes of $M$. jourdanei and those of other digeneans, the present study allowed observing variations of some characters.

Spermiogenesis of $M$. jourdanei begins with the formation of the differentiation zone at the periphery of each early spermatid. This zone is delimited by a ring of arched membranes and contains the intercentriolar body between two centrioles, which are associated to striated rootlets. This differentiation zone characterises the spermiogenesis of neodermatans (see Justine 2003). Each centriole gives rise to a flagellum that grows orthogonally to a median cytoplasmic process before fusing with it. A flagellar rotation of $90^{\circ}$ was described in all microphalloidean species studied to date (see Table 1) and also in other digeneans [e.g. Opecoeloides furcatus (Bremser in Rudolphi, 1819) by Miquel et al. (2000), Poracanthium furcatum Dollfus, 1948 by Levron et al. (2004b), Dicrocoelium dendriticum (Rudolphi, 1819) by Cifrian et al. (1993), Corrigia vitta (Dujardin, 1845) by Robinson and Halton (1982), Troglotrema acutum (Leuckart, 1842) by Miquel et al. (2006), Neoapocreadium chabaudi Kohn et Fernandes, 1982 by Kacem et al. (2010), or Deropristis inflata (Molin, 1859 ) by Foata et al. (2007)]. In other digeneans a flagellar rotation greater than $90^{\circ}$ was described. This is the case of Helicometra fasciata (Rudolphi, 1819), Fasciola hepatica Linnaeus, 1758, Nicolla wisniewskii (Slusarski, 1958), Dicrocoelium hospes (Looss, 1907), Monorchis parvus Looss, 1902, and Crepidostomum metoecus (Braun, 1900) (Levron et al. 2003, 2004c, Ndiaye et al. 2003, Agostini et al. 2005, Quilichini et al. 2007a,b). The importance of this flagellar rotation resides in the comparison between trematodes and cestodes. In fact, in the
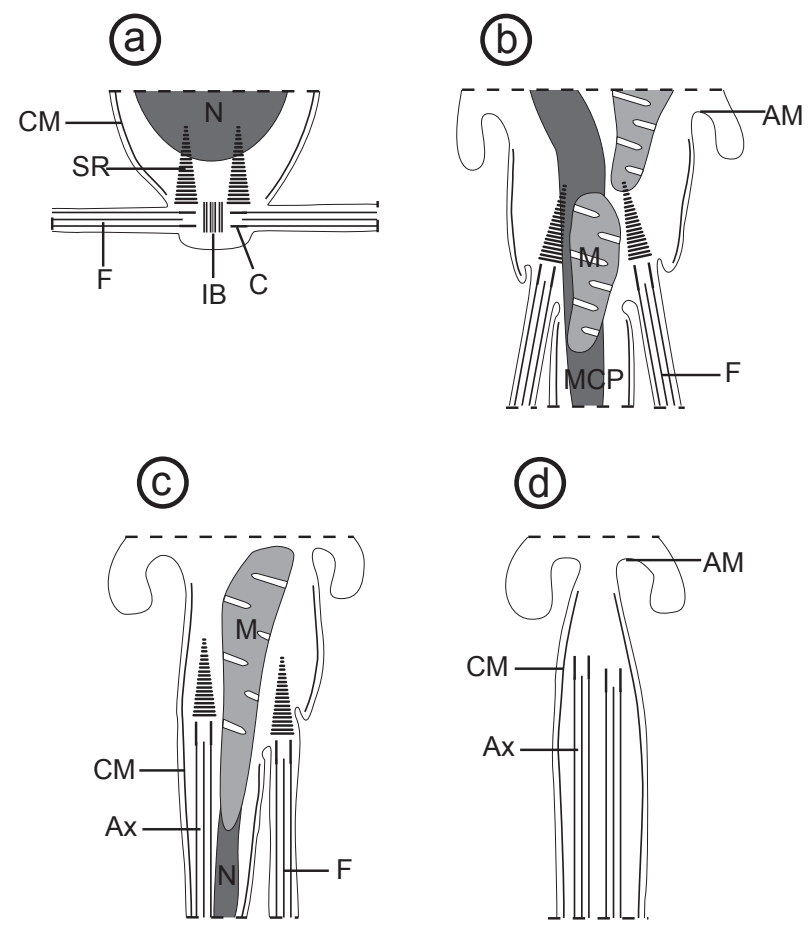

Fig 3. Schematic reconstruction of the spermiogenesis of Mediogonimus jourdanei. Abbreviations: AM - arched membranes; $\mathrm{Ax}$-axoneme; $\mathrm{C}$ - centriole; $\mathrm{CM}$ - cortical microtubules; $\mathrm{F}$ - flagellum; IB - intercentriolar body; $\mathrm{M}$-mitochondrion; $\mathrm{MCP}$ - median cytoplasmic process; $\mathrm{N}$ - nucleus; $\mathrm{SR}$ - striated rootlets.

cestodes the flagellar rotation decreases from $90^{\circ}$ until $0^{\circ}$ in some cyclophyllideans (see Miquel et al. 2009). Nevertheless, some cestodes present a flagellar rotation greater than $90^{\circ}$ (Bruňanská et al. 2006, Miquel et al. 2008). All these aspects allow interpreting this variability as a gradual reduction of the angle of rotation of free flagellum/a from the more basal to the more evolved Platyhelminthes (see Miquel et al. 2006).

The intercentriolar body is another plesiomorphic character present in the Digenea and also in most cestodes, except for tetrabothriideans and cyclophyllideans (Justine $1998,2001)$. The variability in the number of its constitutional plates according to parasitic Platyhelminthes emphasises its importance for phylogenetic purposes (see Bakhoum et al. 2011a, b). In fact, some aspidogastreans present an intercentriolar body with 11 electron-dense plates (see Levron et al. 2009). In digeneans most species present an intercentriolar body with seven electrondense plates as described in M. jourdanei and other microphalloideans (Table 1). However, an intercentriolar body with nine electron-dense layers has been described in Cryptocotyle lingua (Creplin, 1825) and in M. parvus (Rees 1979, Levron et al. 2004c). Moreover, Levron et al. (2003) observed five to seven electron-dense layers in H. fasciata and Foata et al. (2007) described six electrondense layers in $D$. inflata. The absence of this character 

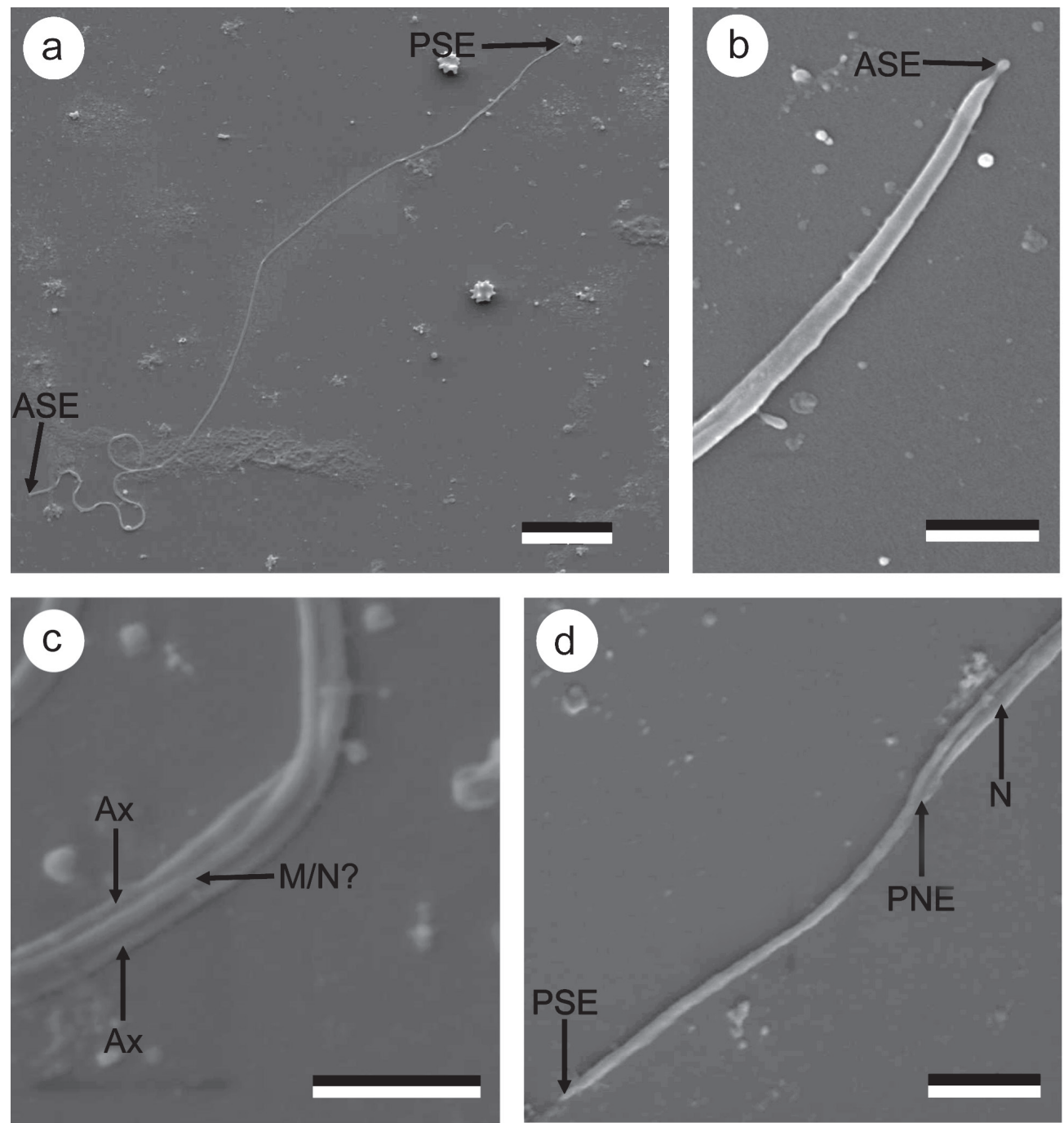

Fig 4. Scanning electron micrographs of the spermatozoon of Mediogonimus jourdanei. a - Entire spermatozoon; $\mathbf{b}$ - Morphology of anterior spermatozoon extremity; $\mathbf{c}$ - Median region of the spermatozoon exhibiting both axonemes with mitochondrion and/or nucleus; d - Posterior spermatozoon extremity; note the posterior nuclear extremity. Abbreviations: ASE - anterior spermatozoon extremity; Ax - axoneme; $\mathrm{M}$ - mitochondrion; $\mathrm{N}$ - nucleus; PNE - posterior nuclear extremity; PSE - posterior spermatozoon extremity. Scale bars: $\mathrm{a}=20 \mu \mathrm{m} ; \mathrm{b}, \mathrm{d}=2 \mu \mathrm{m} ; \mathrm{c}=3 \mu \mathrm{m}$.

is reported in some schistosomatids and didymozoids (Justine and Mattei 1984, Pamplona-Basilio et al. 2001). Within cestodes, which are considered the most evolved Platyhelminthes, a gradual reduction of the intercentriolar body is also observed (Justine 2001, Levron et al. 2010)

In the mature spermatozoon of $M$. jourdanei, as in other digeneans, the intercentriolar body and the striated rootlets are absent. According to Burton (1972) these structures remain in the residual cytoplasm after the total constriction of the ring of arched membranes or degenerate by a process of depolymerisation (see Justine and Mattei 1982, Levron et al. 2004c).

\section{Spermatozoon}

The mature spermatozoon of $M$. jourdanei presents the principal structures described previously in the male gamete of digeneans. Like the remaining microphalloideans described to date, the mature spermatozoon of $M$. jourdanei exhibits two axonemes of different length presenting the 9+"1" pattern of trepaxonematans (Ehlers 1984), a nucleus, one mitochondrion, two sets of parallel cortical microtubules, an external ornamentation accompanied by spine-like bodies, and granules of glycogen irregularly distributed along the spermatozoon except for the anterior extremity. It is interesting to remark that some of these characters and also the morphology of both extremities could be potential candidates for phylogenetic analysis.

The anterior spermatozoon extremity of $M$. jourdane $i$ exhibits two centrioles corresponding to two axonemes. Such description is also reported in Microphallus primas (Jägerskiöld, 1908) by Castilho and Barandela (1990), contrarily to the remaining microphalloideans that present only a single axoneme (see Table 1) as most digeneans studied to date (see Agostini et al. 2005, Quilichini et al. 

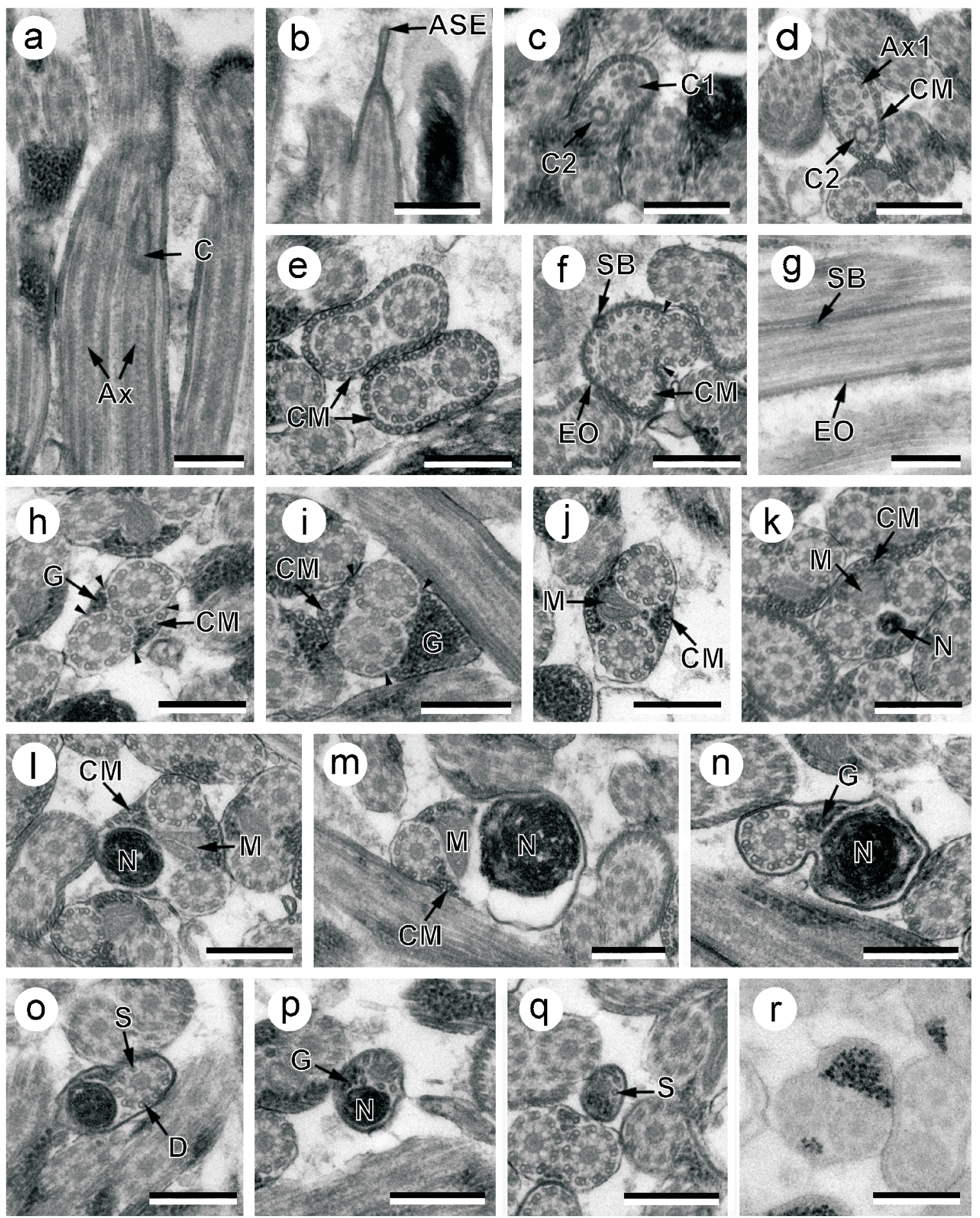

Fig 5. Transmission electron micrographs of the spermatozoon of Mediogonimus jourdanei. $\mathbf{a}, \mathbf{b}$ - Longitudinal sections of the anterior spermatozoon extremity; $\mathbf{c}-\mathbf{e}$-Cross-sections showing the progressive appearance of the first and second axoneme; note the continuous layer of cortical microtubules surrounding both centrioles and/or axonemes; $\mathbf{f}, \mathbf{g}$-Cross and longitudinal sections in the ornamented area exhibiting the spine-like body; arrowheads indicate the presence of only two attachment zones; $\mathbf{h}, \mathbf{i}-$ Transitional zone between regions I and II of the spermatozoon; note the appearance of glycogen granules; arrowheads indicate the presence of four attachment zones; $\mathbf{j}-\mathbf{l}$ - Several cross-sections of region II showing the presence of nucleus, mitochondrion, cortical microtubules, both axonemes and granules of glycogen; $\mathbf{m}$ - Cross-section of the posterior area of region II characterized by the disappearance of one axoneme; $\mathbf{n}-\mathbf{q}$ - Serial cross-sections of region III exhibiting only one axoneme, nucleus and glycogen granules; note the absence of cortical microtubules; $\mathbf{r}$ - Cross-section showing the result of Thiéry staining for glycogen. Abbreviations: ASE - anterior spermatozoon extremity; $\mathrm{Ax}$ - axoneme; $\mathrm{Ax} 1$ - first axoneme; $\mathrm{C}$ - centriole; $\mathrm{C} 1$ - first centriole; $\mathrm{C} 2$ - second centriole; $\mathrm{CM}$ - cortical microtubules; D - doublet; EO - external ornamentation; $\mathrm{G}$ - granules of glycogen; $\mathrm{M}$ - mitochondrion; $\mathrm{N}$ - nucleus; $\mathrm{S}$ - singlet; SB - spine-like body. Scale bars: $\mathrm{a}-\mathrm{r}=0.3 \mu \mathrm{m}$. 


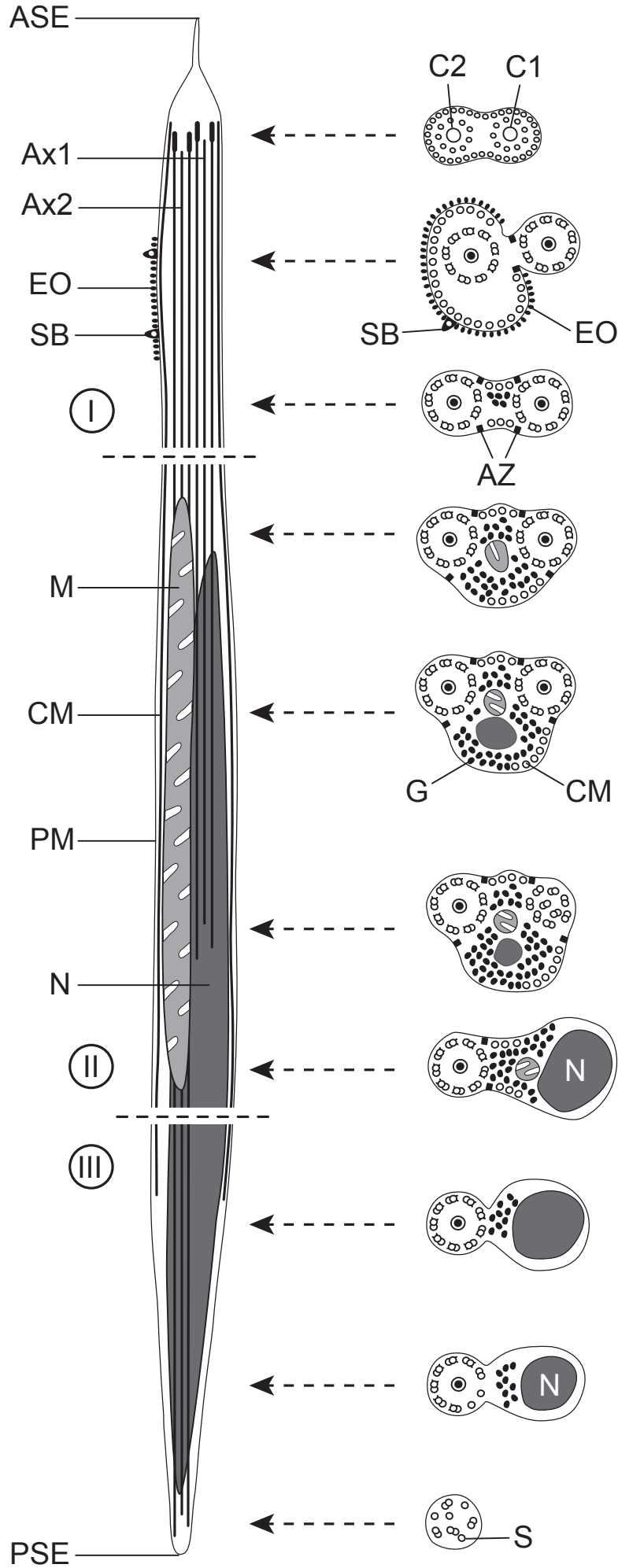

Fig 6. Schematic illustration of the mature spermatozoon of $\mathrm{Me}$ diogonimus jourdanei. Abbreviations: ASE - anterior spermatozoon extremity; Ax1 - first axoneme; Ax 2 - second axoneme; $\mathrm{AZ}$ - attachment zone; $\mathrm{C} 1$ - first centriole; $\mathrm{C} 2$ - second centriole; $\mathrm{CM}$ - cortical microtubules; $\mathrm{EO}$ - external ornamentation; $\mathrm{G}$ - granules of glycogen; $\mathrm{M}$-mitochondrion; $\mathrm{N}$-nucleus; PM - plasma membrane; PSE - posterior spermatozoon extremity; S - singlet; SB - spine-like body.
2009). Additionally, a different morphology of the anterior spermatozoon extremity has been recently evidenced by Kacem et al. (2010) in $N$. chabaudi. The latter authors observed that the anterior tip of the spermatozoon in this species is constituted by cortical microtubules accompanied by external ornamentation.

It is also noticeable to remark the absence of glycogen granules in all sections between the anterior tip of the spermatozoon and the ornamented area. We think that the lack of glycogen could be used in some cases to locate sections belonging to the anterior region of the spermatozoon. This variability in the morphology of the anterior spermatozoon extremity emphasises the importance of this region in the analysis of relationships within the Digenea.

The external ornamentation, present in the anterior region of the spermatozoon, represents a structure generally described in the mature spermatozoon of digeneans (see Miquel et al. 2006, Bakhoum et al. 2011b). However, external ornamentation of the plasma membrane is not exclusive to digeneans. A similar structure was reported in the polyopisthocotylean Pseudomazocraes monsivaisae Caballero et Bravo, 1955 by Justine and Mattei (1985).

With respect to digeneans, Quilichini et al. (2007c) proposed two different groups of digeneans according to the localisation of external ornamentations. However, there are some digeneans without external ornamentation in the sperm cell (see Cifrian et al. 1993, Levron et al. 2003) and it is also remarkable the recent description of a species presenting an external ornamentation throughout the full length of the anterior region (see Kacem et al. 2010). This variability highlights the need for more ultrastructural studies that may allow establishing different patterns according to different families or superfamilies.

The external ornamentation is generally accompanied by cortical microtubules as described in M. jourdanei (present study) and also in other microphalloidean species, except for Maritrema linguilla and Ganeo tigrinum (see Table 1). Therefore, the systematic status of the latter genera is controversial (see Tkach et al. 2003, Jones 2008).

In some digeneans presenting more than one mitochondrion, the external ornamentation appears in the mitochondrial region accompanied by cortical microtubules and spine-like bodies. For example, such description is observed in the troglotrematid T. acutum (Miquel et al. 2006), or in the cryptogonimids S. elongata (see Quilichini et al. 2009), and Anisocoelium capitellatum (Rudolphi, 1819) (Ternengo et al. 2009). Thus, the presence, absence and the variability in the disposition of the external ornamentation are other aspects of importance to use for achieving a better understanding of phylogenetic relationships within the digeneans at a family or superfamily levels.

In the ornamented area, some electron-dense elements appear under the cytoplasmic membrane. Miquel et al. 
Table 1. Spermatological characters in the superfamily Microphalloidea.

\begin{tabular}{|c|c|c|c|c|c|c|c|c|}
\hline \multicolumn{9}{|c|}{ Spermatological characters } \\
\hline Families and species & IB & $\mathrm{AZ}$ & FR & EO & & 1 ASE & PSE & References \\
\hline \multicolumn{9}{|l|}{ Faustulidae } \\
\hline Pronoprymna ventricosa & & & & + & -1 & $1 \mathrm{Ax}$ & $1 \mathrm{Ax}$ & Quilichini et al. (2007c) \\
\hline \multicolumn{9}{|l|}{ Lecithodendriidae } \\
\hline Ganeo tigrinum & & & & - & -1 & ? ? & $1 \mathrm{Ax}$ & Sharma and Rai (1995) \\
\hline \multicolumn{9}{|l|}{ Microphallidae } \\
\hline Microphallus primas & $?$ & 4 & $?$ & + & -1 & $2 A x$ & $1 \mathrm{Ax}$ & Castilho and Barandela (1990) \\
\hline Maritrema linguilla & $?$ & 4 & $90^{\circ}$ & - & -2 & $2 ?$ & $1 \mathrm{Ax}$ & Hendow and James (1988) \\
\hline \multicolumn{9}{|l|}{ Phaneropsolidae } \\
\hline Postorchigenes gymnesicus & 7 & 4 & $90^{\circ}$ & + & -2 & $1 A x$ & $1 \mathrm{Ax}+\mathrm{G}$ & Gracenea et al. (1997) \\
\hline \multicolumn{9}{|l|}{ Prosthogonimidae } \\
\hline Mediogonimus jourdanei & 7 & 4 & $90^{\circ}$ & + & +1 & $2 A x$ & $1 \mathrm{Ax}$ & Present study \\
\hline \multicolumn{9}{|l|}{ Zoogonidae } \\
\hline Diphterostomum brusinae & 7 & 4 & $90^{\circ}$ & + & -1 & $1 \mathrm{Ax}$ & $\mathrm{N}+\mathrm{G}$ & Levron et al. (2004a) \\
\hline
\end{tabular}

Abbreviations: ASE - anterior spermatozoon extremity; Ax - axoneme; AZ - attachment zone; EO - external ornamentation; FR - flagellar rotation; $\mathrm{G}$ - granules of glycogen; IB - intercentriolar body; M - mitochondrion; $\mathrm{N}$ - nucleus; PSE - posterior spermatozoon extremity; SB - spine-like body.

(2000) reported such structures named spine-like bodies for the first time in the spermatozoon of the opecoelid $O$. furcatus. In all digeneans with spine-like bodies, this structure is located in the anterior area of the spermatozoon, being usually associated with the external ornamentation of the plasma membrane. Nevertheless, in N. chabau$d i$ the ornamented zone is anterior to the spine-like bodies (Kacem et al. 2010). Similar structures were previously observed in the spermatozoon of other digeneans. Concerning the superfamily Microphalloidea, spine-like bodies were observed in $M$. jourdanei only (present study). In fact, the observation of micrographs published in older studies reveals several cross-sections where electrondense structures are present (probably spine-like bodies), for example in the anterior region of the spermatozoon of Haematoloechus medioplexus Stafford, 1902 (Justine and Mattei 1982). Unfortunately, the latter authors did not mention these electron-dense structures. Thus, it is possible that in several older studies spine-like bodies have been omitted or misinterpreted as artifacts.

The spine-like bodies seem to be very interesting at a family, superfamily or order level. Much like external ornamentations, some authors have suggested that the formation of spine-like bodies takes place in the last stages of spermiogenesis (Miquel et al. 2000) as observed in M. jourdanei. However, in Diplodiscus subclavatus (Pallas, 1760) and Rubenstrema exasperatum (Rudolphi, 1819), spine-like bodies are observed at an early stage of spermiogenesis, before the fusion of both flagella with the median cytoplasmic process (Bakhoum et al. 2011a, b).

Concerning mitochondria, several viewpoints have been given to explain their number in the mature spermatozoon of Digenea. Burton (1972) argued that the mitochondria observed in the differentiation zone during spermiogenesis fuse and form one mitochondrion after their migration within the median cytoplasmic process. In M. jourdanei, while several mitochondria migrate along the spermatid in the late stage of spermiogenesis, only one mitochondrion was observed in the mature spermatozoon. In the Microphalloidea, one mitochondrion has been described in three species (see Table 1). This is also the case in most digenean species (see Quilichini et al. 2007a). The real difficulty in evaluating the number of mitochondria lies in the impossibility of observing their entire form in longitudinal sections. However, several authors assume the existence of more than one mitochondrion after making logical interpretations of many cross and longitudinal sections. For instance, two mitochondria were observed in the spermatozoon of the microphalloideans Postorchigenes gymnesicus Mas-Coma, Bargues et Esteban, 1981 (Gracenea et al. 1997) and M. linguilla (Hendow and James 1988), but also in other digeneans such as F. hepatica (Ndiaye et al. 2003), D. hospes (Agostini et al. 2005) or T. acutum (Miquel et al. 2006). Three mitochondria were described in the male gamete of $\mathrm{Ba}$ sidiodiscus ectorchus Fischthal et Kuntz, 1959, Sandonia sudanensis McClelland, 1957, E. squamula and Anisocoelium capitellatum Rudolphi, 1819 (Ashour et al. 2007, Bakhoum et al. 2009, Ternengo et al. 2009). The number of mitochondria and their location raise several controversies, which have led researchers to propose the use of some techniques such as mitochondria labelling to assess the real variability in the number of mitochondria (see Miquel et al. 2006).

The posterior spermatozoon extremity also presents a great variability. In $M$. jourdanei the posterior spermatozoon extremity is devoid of cortical microtubules and exhibits one of the axonemes. Within the superfamily, the spermatozoon of all the species described presents a single axoneme in the posterior extremity except for Diphterostomum brusinae (Stossich, 1888) (Levron et al. 2004a), which contains the nucleus. Quilichini et al. (2010) have proposed three morphological types of spermatozoon posterior extremities according to the relative position of several characters. In other study, Bakhoum et al. (2011b) proposed the use of only the terminal character to de- 
fine the posterior spermatozoon extremity, instead of the character sequence toward the terminal extremity. These morphological differences of the posterior spermatozoon extremity could be interesting arguments to include in a future phylogenetic analysis of the Digenea.

A comparison of ultrastructural studies with molecular analyses shows some concordances in the Microphalloidea. In a phylogenetic analysis of this superfamily based on molecular data, Tkach et al. (2003) discuss the incongruent status of the genus Maritrema. In our study, the global analysis of the studied microphalloidean species emphasises that external ornamentation is a significant difference between the ultrastructural organisation of spermatozoa of M. primas (Castilho and Barandela 1990), P. gymnesicus (Gracenea et al. 1997), D. brusinae (Levron et al. 2004a), Pronoprymna ventricosa (Rudolphi, 1819) (Quilichini et al. 2007c) and M. jourdanei (present study), and that of the spermatozoa of the remaining species, G. tigrinum (Sharma and Rai 1995) and M. linguilla (Hendow and James 1988). Spermatozoal characters cor- roborate that the systematic position of Maritrema is confusing, in agreement with the above mentioned molecular study (Tkach et al. 2003). This is also the case of the genus Ganeo, excluded to the family Lecithodendridae Lühe, 1901 and considered incertae sedis by Bray (2008). In this context, more ultrastructural studies, particularly those of species belonging to the unexplored families of Microphalloidea would be useful to highlight ultrastructural characters of interest at the superfamily level.

Acknowledgements. Authors wish to thank the staff of the Nature Reserve of Py (Claude Guisset and David Morichon, in particular) (Pyrenean Mountains, France) for their hospitality and valuable help during the fieldwork. We also thank Nuria Cortadellas and Almudena García from the "Unitat de Microscòpia, Facultat de Medicina, Centres Científics i Tecnològics de la Universitat de Barcelona (CCiTUB)" for their support in the preparation of samples. This study was partially supported by the DURSI Project 2009SGR-403. A.J.S. Bakhoum benefits from a MAEC-AECID doctoral grant (2010-11, No. 0000538055).

\section{REFERENCES}

Agostini S., Miquel J., Ndiaye P.I., Marchand B. 2005: Dicrocoelium hospes Looss, 1907 (Digenea, Dicrocoeliidae): spermiogenesis, mature spermatozoon and ultrastructural comparative study. Parasitol. Res. 96: 38-48.

Ashour A.A., Garo K., Gamil I.S. 2007: Spermiogenesis in two paramphistomes from Nile fish in Egypt: an ultrastructural study. J. Helminthol. 81: 219-226.

BÂ C.T., Marchand B. 1995: Spermiogenesis, spermatozoa and phyletic affinities in the Cestoda. In: B.G.M. Jamieson, J. Ausió and J.-L. Justine (Eds.), Advances in spermatozoal phylogeny and taxonomy. Mém. Mus. Natl. Hist. Nat. 166: 87-95.

Bakhoum A.J.S., BÂ C.T., Fournier-Chambrillon C., Torres J., Fournier P., Miquel J. 2009: Spermatozoon ultrastructure of Euryhelmis squamula (Rudolphi, 1819) (Digenea, Opisthorchioidea, Heterophyidae), an intestinal parasite of Mustela vison (Carnivora, Mustelidae). Rev. Ibero-latinoam. Parasitol. 1: $32-45$.

Bakhoum A.J.S., Bâ C.T., Shimalov V.V., Torres J., Miquel J. 2011b: Spermatological characters of the digenean Rubenstrema exasperatum (Rudolphi, 1819) (Plagiorchioidea, Omphalometridae). Parasitol. Res. 108: 1283-1293.

Bakhoum A.J.S., Torres J., Shimalov V.V., BÂ C.T., Miquel J. 2011a: Spermiogenesis and spermatozoon ultrastructure of Diplodiscus subclavatus (Pallas, 1760) (Paramphistomoidea, Diplodiscidae), an intestinal fluke of the pool frog Rana lessonae (Amphibia, Anura). Parasitol. Int. 60: 64-74.

BEDFORD J.M. 1975: The functional anatomy of the spermatozoon. Proceedings of the Second International Symposium, Wennergren Center, Stockholm, August 1973: xi 373 pp.

BraY R.A. 2008: Superfamily Microphalloidea Ward, 1901. In: R.A. Bray, A. Jones and D.I. Gibson (Eds.), Keys to the Trematoda. Vol. 3. CABI, Wallingford, UK, pp. 447-450.

Brooks D.R., Bandoni S.M., Macdonald C.A., O'Grady R.T. 1989: Aspects of the phylogeny of the Trematoda Rudolphi, 1808 (Platyhelminthes: Cercomeria). Can. J. Zool. 67: 26092624.
Brooks D.R., O'Grady R.T., Glen D.R. 1985: Phylogenetic analysis of the Digenea (Platyhelminthes: Cercomeria) with comments on their adaptative radiation. Can. J. Zool. 63: 411-443.

Bruñanská M., Scholz T., Dezfuli B.S., Poddubnaya L.G. 2006: Spermiogenesis and sperm ultrastructure of Cyathocephalus truncatus (Pallas, 1781) Kessler, 1868 (Cestoda: Spathebothriidea). J. Parasitol. 92: 884-892.

BURTON P.R. 1972: Fine structure of the reproductive system of a frog lung-fluke. III. The spermatozoon and its differentiation. J. Parasitol. 58: 68-83.

Castilho F., Barandela T. 1990: Ultrastructural study on the spermiogenesis and spermatozoon of the metacercariae of $\mathrm{Mi}$ crophallus primas (Digenea), a parasite of Carcinus maenas. Mol. Reprod. Dev. 25: 140-146.

Cifrian B., Garcia-Corrales P., Martinez-Alos S. 1993: Ultrastructural study of the spermatogenesis and mature spermatozoa of Dicrocoelium dendriticum (Plathelminthes, Digenea). Parasitol. Res. 79: 204-212.

Cribb T.H., Bray R.A., Littlewood D.T.J., Pichelin S.P., Herniou E.A. 2001: The Digenea. In: D.T.J. Littlewood and R.A. Bray (Eds.), Interrelationships of the Platyhelminthes, Taylor and Francis, London, UK, pp. 168-185.

Ehlers U. 1984: Phylogenetisches System der Plathelminthes. Verh. Natwiss. Ver. Hamburg, NF, 27: 291-294.

Foata J., Quilichini Y., Marchand B. 2007: Spermiogenesis and sperm ultrastructure of Deropristis inflata Molin, 1859 (Digenea, Deropristidae), a parasite of Anguilla anguilla. Parasitol. Res. 101: 843-852.

Gracenea M., Ferrer J.R., González-Moreno O., Trullols M. 1997: Ultrastructural study of spermatogenesis and spermatozoon in Postorchigenes gymnesicus (Trematoda, Lecithodendriidae). J. Morphol. 234: 223-232.

Hendow H.T., James B.L. 1988: Ultrastructure of spermatozoon and spermatogenesis in Maritrema linguilla (Digenea: Microphallidae). Int. J. Parasitol. 18: 53-63. 
Jones A. 2008: Family Prosthogonimidae Lühe, 1909. In: R.A Bray, D.I Gibson and A. Jones (Eds.), Keys to the Trematoda. Vol. 3. CABI, Wallingford, UK, pp. 577-590.

Justine J.-L. 1998: Systématique des grands groupes de plathelminthes parasites: quoi de neuf? Bull. Soc. Fr. Parasitol. 16: $34-52$.

Justine J.-L. 2001: Spermatozoa as phylogenetic characters for the Platyhelminthes. In: D.T.J. Littlewood and R.A. Bray (Eds.), Interrelationships of the Platyhelminthes. Taylor and Francis, London, UK, pp. 231-238.

Justine J.-L. 2003: Ultrastructure des spermatozoïdes et phylogénie des Neodermata. In: C. Combes and J. Jourdane (Eds.), Taxonomie, Écologie et Évolution des Métazoaires Parasites. PUP, Perpignan, France, pp. 359-380.

Justine J.-L., Mattei X. 1982: Réinvestigation de l'ultrastructure du spermatozoïde d'Haematoloechus (Trematoda: Haematoloechidae). J. Ultrastr. Res. 81: 322-332.

Justine J.-L., Mattei X. 1984: A typical spermiogenesis in a parasitic flatworm, Didymozoon (Trematoda: Digenea: Didymozoidae). J. Ultrastr. Res. 87: 106-111.

Justine J.-L., Mattei X. 1985: Particularités ultrastructurales des spermatozoïdes de quelques Monogènes Polyopisthocotylea. Ann. Sci. Nat. Zool., Paris, 7: 143-152.

Kacem H., Bakhoum A.J.S., Torres J., Neifar L., Miquel J. 2010: Spermiogenesis and ultrastructure of the spermatozoon of Neoapocreadium chabaudi Kohn \& Fernandes, 1982 (Digenea, Apocreadiidae), a parasite of Ballistes capriscus (Pisces, Teleostei). Parasitol. Int. 59: 358-366.

Levron C., Miquel J., Oros M., Scholz T. 2010: Spermatozoa of tapeworms (Platyhelminthes, Eucestoda): advances in ultrastructural and phylogenetic studies. Biol. Rev. 85: 523-543.

Levron C., Suchanová E., Poddubnaya L., Oros M., Scholz T. 2009: Spermatological characters of the aspidogastrean Aspidogaster limacoides Diesing, 1835. Parasitol. Res. 105: 77-85.

Levron C., Ternengo S., Marchand B. 2003: Ultrastructure of spermiogenesis and the spermatozoon of Helicometra fasciata (Digenea, Opecoelidae), a parasite of Labrus merula (Pisces, Teleostei). Acta Parasitol. 48: 255-264.

Levron C., Ternengo S., Marchand B. 2004a: Spermiogenesis and sperm ultrastructure of Diphterostomum brusinae (Digenea, Zoogonidae), a parasite of Diplodus annularis (Pisces, Teleostei). Parasitol. Res. 94: 147-154.

Levron C., Ternengo S., Marchand B. 2004b: Spermiogenesis and sperm ultrastructure of Poracanthium furcatum (Digenea, Opecoelidae), a parasite of Mullus surmuletus (Pisces, Teleostei). Acta Parasitol. 49: 190-200.

Levron C., Ternengo S., Marchand B. 2004c: Ultrastructure of spermiogenesis and the spermatozoon of Monorchis parvus Looss, 1902 (Digenea, Monorchiidae), a parasite of Diplodus annularis (Pisces, Teleostei). Parasitol. Res. 93: 102-110.

Miquel J., Fournier-Chambrillon C., Fournier P., Torres J. 2006: Spermiogenesis and spermatozoon of the cranial digenean Troglotrema acutum (Leuckart, 1842). J. Parasitol. 92: 441-453.

Miquel J., Nourrisson C., Marchand B. 2000: Ultrastructure of spermiogenesis and the spermatozoon of Opecoeloides furcatus (Trematoda, Digenea, Opecoelidae), a parasite of Mullus barbatus (Pisces, Teleostei). Parasitol. Res. 86: 301-310.

Miquel J., Świderski Z., Foronda P., Torres J., Feliu C. 2009: Ultrastructure of spermatogenesis of Taenia taeniaeformis (Batsch, 1786) (Cestoda, Cyclophyllidea, Taeniidae) and comparison of spermatological characters in the family Taeniidae Ludwig, 1886. Acta Parasitol. 54: 230-243.
Miquel J., Świderski Z., Mackiewicz J.S., Ibraheem M.H. 2008: Ultrastructure of spermiogenesis in the caryophyllidean cestode Wenyonia virilis Woodland, 1923, with re-assessment of flagellar rotation in Glaridacris catostomi Cooper, 1920. Acta Parasitol. 53: 19-29.

Ndiaye P.I., Miquel J., Fons R., Marchand B. 2003: Spermiogenesis and sperm ultrastructure of the liver fluke Fasciola hepatica L., 1758 (Digenea, Fasciolidae): scanning and transmission electron microscopy, and tubulin immunocytochemistry. Acta Parasitol. 48: 182-194.

Olson P.D., Cribb T.H., Tkach V.V., Bray R.A., Littlewood D.T.J. 2003: Phylogeny and classification of the Digenea (Platyhelminthes: Trematoda). Int. J. Parasitol. 33: 733-755.

Pamplona-Basilio M.C., Baptista-Farias M.F.D., Kohn A. 2001: Spermatogenesis and spermiogenesis in Didymocystis wedli Ariola, 1902 (Didymozoidae, Digenea). Mem. Inst. Oswaldo Cruz 96: 1153-1159.

Quilichini Y., Foata J., Justine J.-L., Bray R.A., Marchand B. 2009: Sperm ultrastructure of the digenean Siphoderina elongata (Platyhelminthes, Cryptogonimidae) intestinal parasite of Nemipterus furcosus (Pisces, Teleostei). Parasitol. Res. 105: 87-95.

Quilichini Y., Foata J., Justine J.-L., Bray R.A., Marchand B. 2010: Ultrastructural study of the spermatozoon of Heterolebes maculosus (Digenea, Opistholebetidae), a parasite of the porcupinefish Diodon hystrix (Pisces, Teleostei). Parasitol. Int. 59: 427-434.

Quilichini Y., Foata J., Marchand B. 2007c: Ultrastructural study of the spermatozoon of Pronoprymna ventricosa (Digenea, Baccigerinae), parasite of the twaite shad Alosa fallax Lacepede (Pisces, Teleostei). Parasitol. Res. 101: 1125-1130.

Quilichini Y., Foata J., Orsini A., Marchand B. 2007a: Ultrastructural study of spermiogenesis and the spermatozoon of Crepidostomum metoecus (Digenea: Allocreadiidae), a parasite of Salmo trutta (Pisces: Teleostei). J. Parasitol. 93: 458-468.

Quilichini Y., Foata J., Orsini A., Marchand B. 2007b: Spermiogenesis and spermatozoon ultrastructure of Nicolla wisniewskii (Digenea: Opecoelidae), an intestinal parasite of brown trout Salmo trutta (Pisces: Teleostei). J. Parasitol. 93: 469-478.

Rees F.G. 1979: The ultrastructure of the spermatozoon and spermiogenesis in Cryptocotyle lingua (Digenea: Heterophyidae). Int. J. Parasitol. 9: 405-419.

Reynolds E.S. 1963: The use of lead citrate at high $\mathrm{pH}$ as an electron-opaque stain in electron microscopy. J. Cell Biol. 17: 208-212.

Robinson R.D., HaLton D.W. 1982: Fine structural observations on spermatogenesis in Corrigia vitta (Trematoda: Dicrocoeliidae). Z. Parasitenkd. 68: 53-72.

Sharma P.N., RaI N. 1995: Ultrastructural study on spermatogenesis in Ganeo trigrinum, an intestinal trematode of Rana tigrina. J. Helminthol. 69: 77-84.

Ternengo S., Quilichini Y., Katharios P., Marchand B. 2009: Sperm ultrastructure of the gall bladder fluke Anisocoelium capitellatum (Digenea: Crytogonimidae) a parasite of Uranoscopus scaber (Pisces: Uranoscopidae). Parasitol. Res. 104: 801-807.

THiérY J.P. 1967: Mise en évidence des polysaccharides sur coupes fines en microscopie électronique. J. Microsc. 6: 987-1018.

Tкасh V.V., Littlewood T.D.J., Olson P.D., Kinsella M., ŚWIDERSKi Z. 2003: Molecular phylogenetic analysis of the Microphalloidea Ward, 1901 (Trematoda: Digenea). Syst. Parasitol. 56: 1-15. 